\title{
Premorbid aspirin use is not associated with lower mortality in older inpatients with SARS-CoV-2 pneumonia
}

\author{
Coralie Sullerot $\cdot$ Kevin Bouiller $\cdot$ Caroline Laborde $\cdot$ Marine Gilis $\cdot$ Amélie Fèvre $\cdot$ Arthur Hacquin $\cdot$ \\ Patrick Manckoundia • Florence Hoefler $\cdot$ Messaline Bermejo • Aline Mendes • Christine Serratrice • \\ Virginie Prendki $\cdot$ Stéphane Sanchez $\cdot$ Alain Putot ${ }^{\mathbb{D}} \cdot$ On behalf of ESGIE (European Society of Clinical \\ Microbiology, European Society of Clinical Microbiological and Infectious Diseases, Study Group for \\ Infections in the Elderly)
}

Received: 21 September 2021 / Accepted: 13 December 2021 / Published online: 7 January 2022

(C) The Author(s), under exclusive licence to American Aging Association 2021

\begin{abstract}
Platelet aggregation has been associated with COVID-19 pathogenesis. In older patients hospitalized for SARS-CoV-2 pneumonia, we aimed to investigate the association between aspirin use before admission and the risk of in-hospital all-cause mortality. We performed a retrospective international cohort study in five COVID-19 geriatric units in France and Switzerland. Among 1,357 consecutive hospitalized patients aged 75 or older and testing positive for SARS-CoV-2, we included 1,072 with radiologically confirmed pneumonia. To adjust for confounders, a propensity score for treatment was created, and stabilized inverse probability of treatment weighting
\end{abstract}

C. Sullerot · A. Hacquin - P. Manckoundia - A. Putot Department of Geriatric Internal Medicine, Dijon University Hospital, Dijon, France

K. Bouiller

Department of Infectious Diseases, Besançon University

Hospital, Besançon, France

C. Laborde $\cdot$ A. Fèvre

Department of Geriatric Internal Medicine, Nimes

University Hospital, Nimes, France

M. Gilis

Department of Geriatrics, Besançon University Hospital, Besançon, France

F. Hoefler · M. Bermejo

Department of Internal Medicine and Infectious Diseases,

Troyes Hospital, Troyes, France
(SIPTW) was applied. To assess the association between aspirin use and in-hospital 30-day mortality, SIPTW-adjusted Kaplan-Meier and Cox proportional hazards regression analyses were performed. Of the 1047 patients with SARS-CoV-2 pneumonia and median age 86 years, 301 (28.7\%) were taking aspirin treatment before admission. One hundred forty-seven (34.3\%) patients who had taken aspirin died in hospital within 1 month vs 118 patients (30.7\%) without aspirin. After SIPTW, aspirin treatment was not significantly associated with lower mortality (adjusted hazard ratio: 1.10 [0.81-1.49], $P=.52$ ). Moreover, patients on aspirin had a longer hospital stay and were

\author{
A. Mendes \\ Division of Geriatrics, Geneva University Hospitals, \\ Geneva, Switzerland \\ C. Serratrice $\cdot$ V. Prendki \\ Division of Internal Medicine for the Aged, Geneva \\ University Hospitals, Geneva, Switzerland \\ V. Prendki \\ Division of Infectious Diseases, Geneva University \\ Hospitals, Geneva, Switzerland \\ S. Sanchez \\ Department of Clinical Research, Troyes Hospital, Troyes, \\ France
}
A. Putot $(\bowtie)$
Service de Médecine Interne Gériatrie, Hôpital de
Champmaillot CHU, 21079 Dijon Cedex, France
e-mail: alain.putot@chu-dijon.fr 
more frequently transferred to the intensive care unit. In a large multicenter cohort of older inpatients with SARS-CoV-2 pneumonia, aspirin use before admission did not appear to be associated with an improved prognosis.

Keywords Aspirin - Antiplatelet · Pneumonia · Coronavirus $\cdot$ COVID-19 $\cdot$ Aged $\cdot$ Mortality

\section{Introduction}

The COVID-19 pandemic has caused more than 4.2 million deaths worldwide, $60 \%$ of which occurred in people over 80 years of age. The main cause of death is severe viral pneumonia complicating the infection. Experimental studies have provided evidence of a deleterious excessive inflammatory response, as well as overactivation of the coagulation cascade and platelet aggregation in COVID-19. These mechanisms are thought to be responsible for macro- and microvascular thrombosis, acute cardiovascular (CV) events, and acute respiratory distress syndrome (ARDS), which is the most serious feature of the disease. [1] Except for corticosteroids, [2] the efficacy of treatments currently used in COVID-19 remains uncertain in terms of mortality prevention in very old patients. Given the high frequency of CV complications, coronavirus-induced thrombo-activation could be a promising therapeutic target. Acetylsalicylic acid has anti-inflammatory, antithrombotic, and antiviral activity against DNA and RNA viruses according to the results of in vitro and experimental studies. [3] It is also a well-known and inexpensive molecule. Numerous observational studies have found an association between acetylsalicylic acid use and improved prognosis in adult community-acquired pneumonia. [4-6] Such an association has been also suggested in COVID-19 [7-13] even though recent data from the RECOVERY trial found that aspirin $150 \mathrm{mg}$ introduced at COVID-19 diagnosis had no benefit. [14] However, age and pneumonia severity have been shown to be strongly associated with $\mathrm{CV}$ risk in COVID-19. [15-17] A large retrospective study comparing short-term outcomes in COVID-19 veterans with or without preexisting aspirin prescription [18] highlighted a decrease in overall mortality of over $50 \%$ in individuals prescribed aspirin. Despite the advanced age of the population, these interesting data mostly concerned low-risk ambulatory patients with relatively low 30-day mortality (5\%). To our knowledge, it has not yet been established whether longterm aspirin use is associated with improved prognosis in an older comorbid population at very high $\mathrm{CV}$ risk hospitalized for SARS-CoV-2 pneumonia. We therefore sought to evaluate, through a retrospective multicenter cohort study, whether long-term treatment with acetylsalicylic acid was associated with lower in-hospital mortality in this specific population.

\section{Methods}

Data source and design

We performed a retrospective, multicenter cohort study using hospital records data from the acute geriatric care units of four university hospitals and one regional hospital in France and Switzerland. Data was collected from March 1, 2020, to December 31, 2020, including the first two waves of the COVID-19 pandemic in Europe. Data were extracted from medical records in each hospital and anonymized before release to investigators.

This observational study was conducted in accordance with the Declaration of Helsinki and national standards. The Geneva committee for research ethics was consulted and approved the study. Each participant or his/her referee received an information letter and was invited to express his/her opposition to participation in the study.

\section{Patients}

We included all consecutive patients aged 75 years or older presenting with acute, radiologically confirmed pneumonia, testing positive for SARS-CoV-2 with real-time polymerase chain reaction (RT-PCR) and initially admitted in acute geriatric care units. Patients initially admitted to intensive care units (ICU) were not included. Acute pneumonia was defined according to the American guidelines, [19] in the acute presence of 2 or more of the following signs: new cough, sputum production, dyspnea, pleuritic pain, abnormal temperature $\left(<35.6{ }^{\circ} \mathrm{C}\right.$ or $\left.>37.8{ }^{\circ} \mathrm{C}\right)$, or altered breathing sounds on auscultation, and a new infiltrate on chest imaging. 
There were no exclusion criteria.

Based on previous studies (36\% in-hospital mortality rate, $1 / 2$ exposed/non-exposed ratio) [20, 21] and considering a 0.7 relative hazard as plausible [7] and clinically significant, a total sample size of 847 patients was estimated to provide $80 \%$ power, using a 2-tailed hypothesis at an $\alpha$ level of 0.05 .

Exposure and primary outcome measure

We compared patients who received aspirin treatment at admission (whatever the dose and co-prescriptions), with those who did not receive aspirin treatment. The primary outcome was all-cause in-hospital 30-day mortality.

\section{Data collection and management}

We recorded the following characteristics as potential confounders at admission: hospital center, age, sex, level of independence evaluated by the Katz activity of daily living (ADL) scale, [22] underlying diseases including CV history (myocardial infarction, heart failure, stroke, peripheral artery disease) and Charlson Comorbidity Index, [23] clinical presentation (delay between symptom onset and positive RTPCR test, heart rate, systolic and diastolic blood pressure, temperature, oxygen saturation, oxygen flow, respiratory rate, confusion), biological parameters (leucocyte count, C-reactive protein, albumin, urea, creatinine), prognosis scores (CURB65, [24] Pneumonia Severity Index [25]). Place of acquisition of pneumonia was also recorded: community-acquired pneumonia (CAP), nursing-home-acquired pneumonia (NHAP), and late-onset hospital-acquired pneumonia (HAP), defined as symptom onset occurring after 4 days of hospitalization. [26]

In-hospital management, including acute treatments (corticosteroid therapy with a daily dose $\geq 6 \mathrm{mg}$ of dexamethasone or equivalent, tocilizumab, remdesivir, lopinavir/ritonavir, chloroquine) and antibiotic and palliative treatment (morphine, midazolam) were reported.

Vital status at discharge, hospital length of stay, transfer to ICU, and palliative care requirement were also recorded.

To avoid excluding patients with missing values for several of the potential confounders, multiple imputation was used to handle missing data $(<10 \%$ for all covariates) that were assumed to be missing at random for all covariates (albumin rate, ADL scale, respiratory rate). Missing values were imputed 10 times, by sampling from their posterior predictive distribution, conditional on the observed data. In all subsequent analyses, Rubin's rules were applied to summarize the effect estimates and variances from the 10 different analyses across multiple imputed data sets. [27]

\section{Statistical analysis}

Continuous variables were described using medians and interquartile ranges, and categorical variables were described using frequencies and percentages. Wilcoxon rank-sum, $\chi^{2}$, and log-rank tests were used to evaluate the statistical significance of unadjusted continuous, categorical, and time-to-event data, respectively. All tests were 2 -tailed, and a $P$ value of less than 0.05 was considered statistically significant. Statistical analyses were performed using SPSS 21.0 (IBM Corp, Armonk, NY) and R 4.0.4 software (R Foundation for Statistical Computing, Vienna, Austria).

\section{Propensity model}

Older patients who receive aspirin treatment before the COVID-19 diagnosis tend to have more previous CV disease than those who do not. To account for potential confounding in the association of aspirin use and mortality, we created a propensity score for each patient and applied inverse probability weighting. The propensity score represented the predicted probability of receiving aspirin and was determined using a logistic regression model with aspirin use as the dependent variable and the potential confounders at admission (listed in Table 1) as the independent variables. Each patient's propensity score was then used to create an inverse probability weight for that patient. Stabilized inverse probability of treatment weight (SIPTW) was obtained by multiplying the inverse probability weight by the marginal probability of receiving the actual treatment received (i.e., aspirin treatment or not). [28] After adjusting for these weights, a propensity-weighted sample was created that was more balanced with respect to potential confounders included in the regression model.

Before assessing the outcome, we confirmed that the weighted sample was balanced using the 
Table 1 Characteristics at admission ( $n(\%)$ or median [interquartile range])

\begin{tabular}{|c|c|c|c|c|c|c|c|}
\hline & \multicolumn{4}{|c|}{ Unweighted study population } & \multicolumn{3}{|c|}{ Weighted study population } \\
\hline & Aspirin, $N=301$ & $\begin{array}{l}\text { No aspirin, } \\
N=746\end{array}$ & $P$ & $\begin{array}{l}\text { Standard- } \\
\text { ized differ- } \\
\text { ence }\end{array}$ & Aspirin & No aspirin & $\begin{array}{l}\text { Standard- } \\
\text { ized dif- } \\
\text { ference }\end{array}$ \\
\hline \multicolumn{8}{|l|}{ Hospital center } \\
\hline Center (1) & $122(40.5)$ & $215(28.8)$ & $<.001$ & .252 & $75(25.5)$ & $200(27.5)$ & -.045 \\
\hline Center (2) & $50(16.6)$ & $141(18.9)$ & & -.06 & $54(18.4)$ & $143(19.6)$ & -.03 \\
\hline Center (3) & $53(17.6)$ & $136(18.2)$ & & -.016 & $60(20.4)$ & $143(19.6)$ & .02 \\
\hline Center & $44(14.6)$ & $87(11.7)$ & & .088 & $41(13.9)$ & 99 (13.6) & .009 \\
\hline Center (5) & $32(10.6)$ & $167(22.4)$ & & -.304 & $64(21.8)$ & $143(19.6)$ & .055 \\
\hline \multicolumn{8}{|l|}{ Demographics } \\
\hline Age (years) & 85.4 [81.3-89.3] & 85.9 [80.9-90.3] & .797 & .074 & 86 [81.6-89.7] & $86.1[81.3-90.4]$ & .085 \\
\hline Men & $157(52.2)$ & $353(47.3)$ & .156 & .098 & $152(51.7)$ & $349(48)$ & .074 \\
\hline $\begin{array}{l}\text { Activity of } \\
\text { daily living } \\
\text { scale }\end{array}$ & $5[4-6]$ & $5[3-6]$ & .272 & -.044 & $5.5[3.5-6]$ & 5 [3-6] & -.033 \\
\hline $\begin{array}{l}\text { Community- } \\
\text { acquired } \\
\text { pneumonia }\end{array}$ & $189(62.8)$ & 408 (54.7) & .017 & .164 & $175(59.3)$ & $400(55)$ & .087 \\
\hline $\begin{array}{l}\text { Hospital- } \\
\text { acquired } \\
\text { pneumonia }\end{array}$ & 48 (15.9) & $162(21.8)$ & .033 & -.148 & $60(20.4)$ & $152(20.9)$ & -.012 \\
\hline $\begin{array}{l}\text { Nursing-home } \\
\text { acquired } \\
\text { pneumonia }\end{array}$ & $55(18.3)$ & 169 (22.7) & .118 & -.107 & $54(18.4)$ & $168(23.1)$ & -.114 \\
\hline \multicolumn{8}{|l|}{ Comorbidities } \\
\hline $\begin{array}{c}\text { Myocardial } \\
\text { infarction }\end{array}$ & $75(25.0)$ & 99 (13.3) & $<.001$ & .317 & $52(17.7)$ & $120(16.5)$ & .032 \\
\hline Heart failure & $91(30.5)$ & 209 (28.8) & .576 & .037 & $96(32.8)$ & $215(30.4)$ & .052 \\
\hline $\begin{array}{l}\text { Peripheral } \\
\text { artery disease }\end{array}$ & $62(20.7)$ & $100(13.6)$ & .004 & .196 & $46(15.7)$ & $111(15.5)$ & .006 \\
\hline Stroke & $64(21.5)$ & 144 (19.6) & .507 & .053 & $66(22.5)$ & 157 (22) & .012 \\
\hline Diabetes & $84(28)$ & $173(23.5)$ & .428 & .104 & $80(27.3)$ & $193(26.8)$ & .011 \\
\hline $\begin{array}{l}\text { Chronic } \\
\text { respiratory } \\
\text { disease }\end{array}$ & $45(18.0)$ & $132(21.7)$ & .226 & -.092 & $36(15.1)$ & $119(20.2)$ & -.131 \\
\hline $\begin{array}{l}\text { Chronic kidney } \\
\text { disease }\end{array}$ & $90(30.1)$ & $280(38.1)$ & .012 & -.167 & $102(34.7)$ & $263(36.7)$ & -.042 \\
\hline $\begin{array}{l}\text { Chronic liver } \\
\text { disease }\end{array}$ & $16(5.4)$ & $32(4.3)$ & .660 & .052 & $17(5.8)$ & $32(4.4)$ & .065 \\
\hline $\begin{array}{l}\text { Connective tis- } \\
\text { sue disease }\end{array}$ & $13(4.4)$ & $33(4.5)$ & .928 & -.005 & $12(4.1)$ & $33(4.6)$ & -.024 \\
\hline Peptic ulcer & $9(3)$ & $47(6.4)$ & .030 & -.151 & $11(3.7)$ & $39(5.4)$ & -.079 \\
\hline $\begin{array}{l}\text { Cognitive } \\
\text { disorders }\end{array}$ & $112(37.5)$ & 292 (39.6) & .528 & -.039 & $103(35.2)$ & $288(40)$ & -.099 \\
\hline Hemiplegia & $12(4)$ & $19(2.6)$ & .434 & .082 & $11(3.8)$ & 28 (3.9) & -.005 \\
\hline $\begin{array}{l}\text { Active neo- } \\
\text { plasia }\end{array}$ & $48(16)$ & $131(17.8)$ & .739 & -.048 & $52(17.7)$ & $128(17.8)$ & -.003 \\
\hline $\begin{array}{l}\text { Metastatic } \\
\text { cancer }\end{array}$ & $2(0.8)$ & $18(3)$ & .139 & -.145 & $8(3.4)$ & $15(2.6)$ & .048 \\
\hline
\end{tabular}


Table 1 (continued)

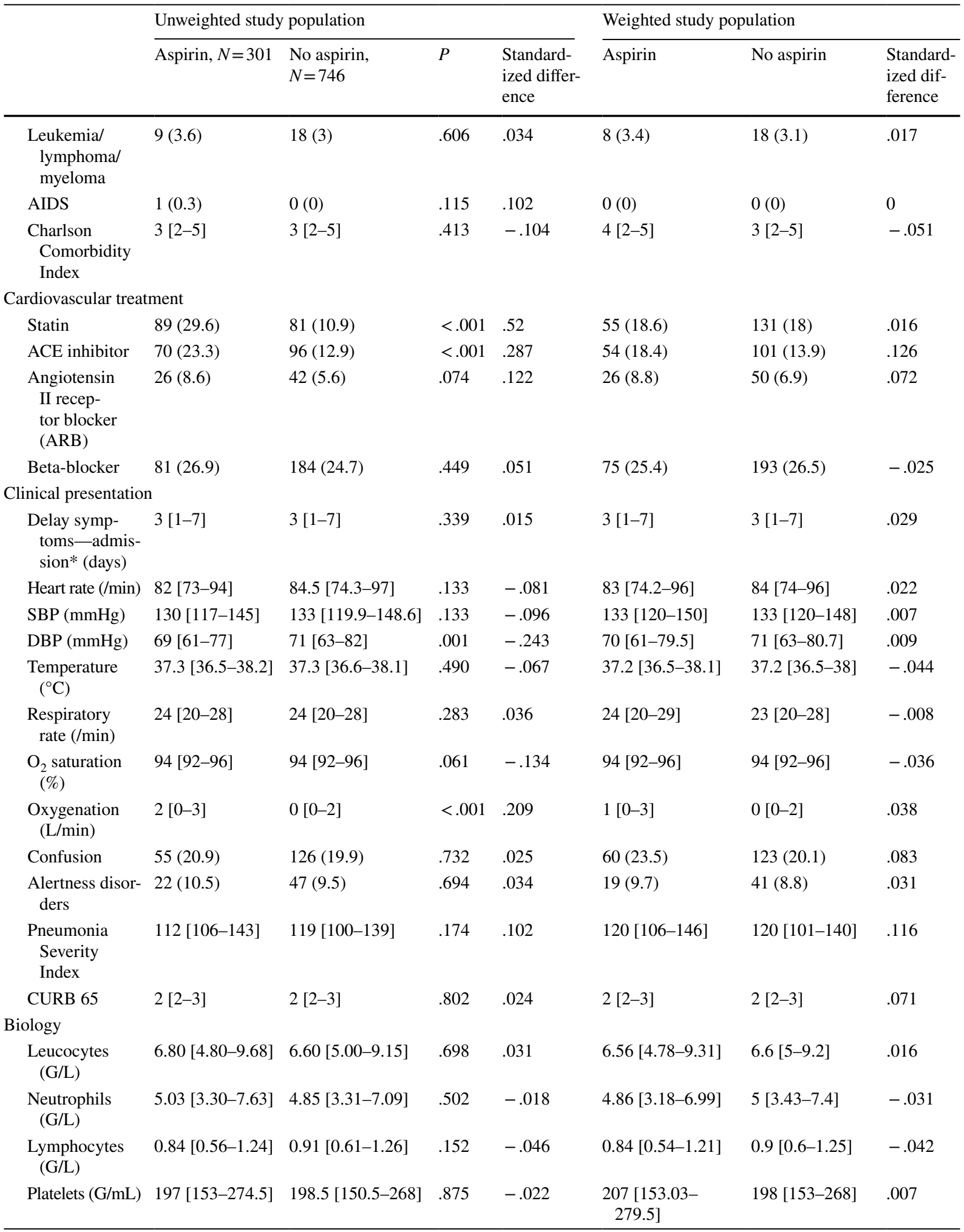


Table 1 (continued)

\begin{tabular}{|c|c|c|c|c|c|c|c|}
\hline & \multicolumn{4}{|c|}{ Unweighted study population } & \multicolumn{3}{|c|}{ Weighted study population } \\
\hline & Aspirin, $N=301$ & $\begin{array}{l}\text { No aspirin, } \\
N=746\end{array}$ & $P$ & $\begin{array}{l}\text { Standard- } \\
\text { ized differ- } \\
\text { ence }\end{array}$ & Aspirin & No aspirin & $\begin{array}{l}\text { Standard- } \\
\text { ized dif- } \\
\text { ference }\end{array}$ \\
\hline $\begin{array}{l}\text { C-reactive pro- } \\
\text { tein }(\mathrm{mg} / \mathrm{L})\end{array}$ & $75[26-132]$ & $64[26-114]$ & .188 & .117 & $65[23-121]$ & $65[26-115]$ & .003 \\
\hline Albumin $(\mathrm{g} / \mathrm{L})$ & $31.3[27-35]$ & $32[28-36]$ & .258 & -.105 & $32[27-36.4]$ & $32[28-36]$ & -.088 \\
\hline Urea (mmol/L) & $9.1[6-13.9]$ & $8.7[6.3-13]$ & .576 & .104 & $9.1[5.8-13.7]$ & $8.6[6.2-13.1]$ & .015 \\
\hline $\begin{array}{r}\text { Creatinine } \\
(\mu \mathrm{mol} / \mathrm{L})\end{array}$ & 94 [71-125] & $90[69-124]$ & .345 & .004 & $95[71-121]$ & $90[69-125]$ & .021 \\
\hline \multicolumn{8}{|l|}{ Chest CT scan } \\
\hline $\begin{array}{l}\text { Alveolar con- } \\
\text { densation }\end{array}$ & $114(37.9)$ & $251(33.6)$ & .473 & .09 & $79(27)$ & $228(31.4)$ & -.096 \\
\hline $\begin{array}{l}\text { Mild lung } \\
\text { injury } \\
(<10 \%)\end{array}$ & $39(13)$ & $73(9.8)$ & .162 & .104 & $38(12.9)$ & $71(9.8)$ & .1 \\
\hline $\begin{array}{l}\text { Moderate } \\
\text { lung injury } \\
(10-25 \%)\end{array}$ & $33(11)$ & $99(13.3)$ & .235 & -.069 & $47(15.9)$ & $97(13.3)$ & .075 \\
\hline $\begin{array}{l}\text { Extensive } \\
\text { lung injury } \\
(25-50 \%)\end{array}$ & $33(11)$ & $96(12.9)$ & .173 & -.058 & $34(11.6)$ & $90(12.4)$ & -.024 \\
\hline $\begin{array}{l}\text { Severe lung } \\
\text { injury } \\
(50-75 \%)\end{array}$ & $25(8.3)$ & $72(9.7)$ & .281 & -.048 & $21(7.1)$ & $65(8.9)$ & -.065 \\
\hline
\end{tabular}

$D B P$, diastolic blood pressure; $P A D$, peripheral artery disease; $S B P$, systolic blood pressure

*Delay between symptoms onset and hospital admission

following parameters: standardized difference, -0.15 to 0.15 ; and variance ratio, 0.5 to 2.0 . [29] We examined overlap plots of the propensity scores by treatment group to ensure that the area of common support was adequate.

\section{Outcomes}

SIPTW-adjusted Kaplan-Meier curves were calculated to compare overall in-hospital 30-day survival between patients who received aspirin treatment and those who did not. We further fitted an SIPTW-adjusted Cox proportional hazards regression model to compute the corresponding hazard ratio. To avoid informative censoring, patients discharged from the hospital were regarded as surviving to 30 days.

\section{Results}

Study population

From March 1, 2020, to December 31, 2020, 1369 consecutive patients over 75 years of age and positive for SARS-CoV2 (RT-PCR) were hospitalized. Among them, 318 did not have pneumonia at admission and 4 refused to participate.

Of the 1047 patients included in the study, 301 (28.7\%) were taking aspirin at admission and 746 were not. As shown in Table 1, the aspirin and noaspirin groups were similar in terms of age (median age (interquartile range): 85.4 (81.3-89.3) vs. 85.9 (80.9-90.3), $P=0.8$ ), gender (men 52\% vs. 47\%, $P=0.16$ ), and comorbidities (Charlson Comorbidity 
Index: $3(2-5)$ vs. $3(2-5), P=0.41)$. However, in the aspirin group, a history of $\mathrm{CV}$ disease was more frequent (myocardial infarction $25 \%$ vs $13.3 \%$, $P<0.001$, peripheral artery disease $20.7 \%$ vs $13.6 \%, P=0.004)$ and $\mathrm{CV}$ treatment was thus more prescribed.

Other similarities between groups included the clinical presentation at admission and the Pneumonia Severity Index (112 [106-143] vs 119 [100-139], $P=0.174)$, as well as biological and CT scan data.

After SIPTW, the differences in the baseline covariates that were apparent in the overall sample were no longer present (Table 1).

Acute treatment during hospital stay is presented in Table 2. Nearly $80 \%$ received antibiotic treatment, $36 \%$ received corticosteroids, and 35\% received morphine therapy. Except for less frequent use of midazolam in patients under aspirin (15.8 vs $18.7 \%$, $P=0.023$ ), acute management did not significantly differ in the two groups after SIPTW.

\section{Outcomes}

After SIPTW, the in-hospital 30-day mortality rate did not significantly differ in the two groups (34.6\% in the aspirin group vs. $30.7 \%$ in the non-aspirin group, $P=0.23$, Table 2). SIPTW-adjusted hazard ratio for in-hospital 30-day mortality in aspirin vs no-aspirin patients was 1.10 [0.81-1.49] $(P=0.52)$. However, hospital stays were significantly longer in patients taking aspirin compared with those who were not (11 [7-20] vs 10 [6-18], $P=0.024)$, and transfer to ICU, although rare, was also more frequent $(7.5 \%$ vs $3.6 \%$, $P=0.007)$. Patients were often given palliative care in both groups ( $15.8 \%$ vs $18.7 \%, P=0.336)$.

SIPTW-adjusted Kaplan-Meier curves are presented in Fig. 1: in-hospital 30-day mortality did not significantly differ between the two groups (log-rank test, $P=0.52$ ).

\section{Discussion}

In this large multicenter study, nearly one-third of patients hospitalized in an acute geriatric setting with SARS-CoV-2 pneumonia had died at 1 month. In this population, long-term aspirin treatment was not associated with a better short-term prognosis.

Despite the poor prognosis in severe COVID-19 and a large number of studies since the start of the pandemic, the treatment options are still limited, especially for frail older patients. Observational and interventional data are increasingly available on the impact of longterm antiplatelet therapy in COVID-19. However, the studies published so far offer conflicting results and few have focused on older comorbid populations, which are

Table 2 In-hospital management and outcomes ( $n(\%)$ or median [interquartile range])

\begin{tabular}{|c|c|c|c|c|c|c|}
\hline & \multicolumn{3}{|c|}{ Unweighted study population } & \multicolumn{3}{|c|}{ Weighted study population } \\
\hline & Aspirin, $N=301$ & No aspirin, $N=746$ & $P$ & Aspirin & No aspirin & $P$ \\
\hline \multicolumn{7}{|l|}{ Therapeutics } \\
\hline Corticosteroids* & $104(34.6)$ & $262(35.1)$ & .861 & $106(36.1)$ & $266(36.6)$ & .872 \\
\hline Tocilizumab & $24(8)$ & $47(6.3)$ & .330 & $14(4.7)$ & $43(5.9)$ & .463 \\
\hline Remdesivir & $40(13.3)$ & $51(6.8)$ & .001 & $17(5.8)$ & $45(6.2)$ & .805 \\
\hline Lopinavir/ritonavir & $37(12.3)$ & $58(7.8)$ & .021 & $29(9.9)$ & $51(7)$ & .125 \\
\hline Chloroquine & $42(14)$ & $67(9)$ & .017 & $27(9.2)$ & $59(8.1)$ & .588 \\
\hline Antibiotic treatment & $243(81.8)$ & $563(76.9)$ & .084 & $239(81.6)$ & $548(76.6)$ & .086 \\
\hline Morphine & $96(31.9)$ & $248(33.2)$ & .674 & $108(36.7)$ & $245(33.7)$ & .356 \\
\hline Midazolam & $42(16.9)$ & $141(23.1)$ & .045 & $37(15.8)$ & 134 (22.9) & .023 \\
\hline \multicolumn{7}{|l|}{ Outcomes } \\
\hline Transfer to intensive care unit & $26(8.6)$ & $27(3.6)$ & .001 & $22(7.5)$ & $26(3.6)$ & .007 \\
\hline Palliative care requirement & $49(19.8)$ & $116(19)$ & .803 & $37(15.8)$ & 109 (18.7) & .336 \\
\hline Hospital stay (days) & $10[6-17]$ & $10[6-18]$ & .997 & $11[7-20]$ & $10[6-18]$ & .024 \\
\hline Death at 30 days & $104(34.6)$ & $229(30.7)$ & .225 & $101(34.4)$ & $224(30.8)$ & .271 \\
\hline
\end{tabular}

${ }^{*}$ Equivalent $\geq 6 \mathrm{mg}$ dexamethasone 
Fig. 1 SIPTW-adjusted Kaplan-Meier curves of in-hospital 30-day survival after SARS-CoV-2 pneumonia in older patients with or without aspirin at admission

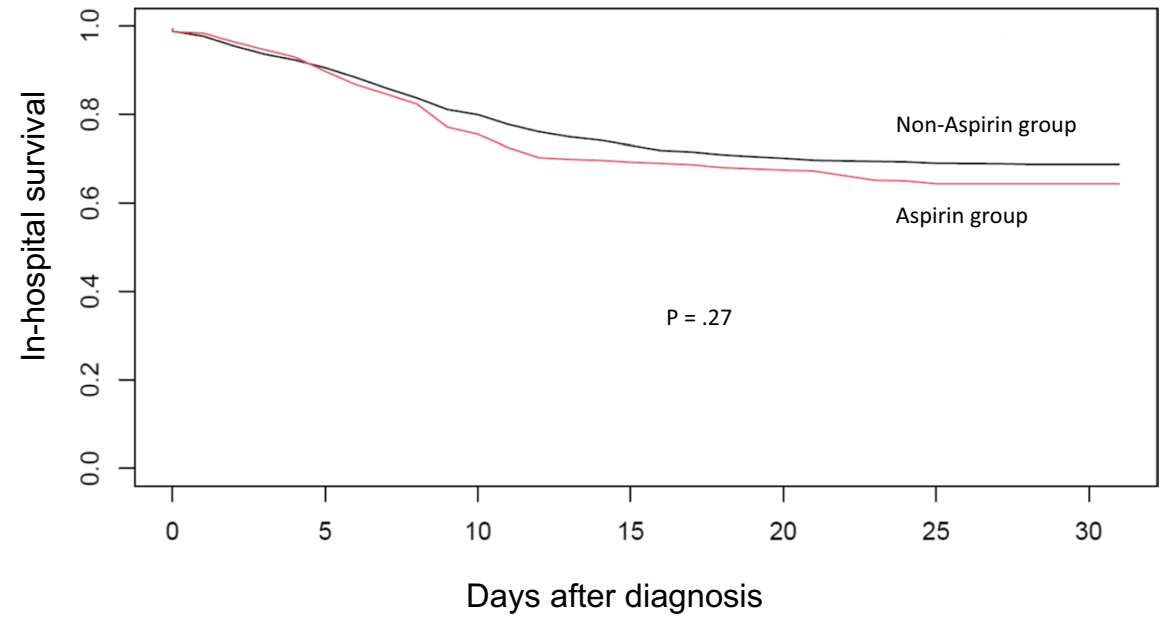

often excluded from randomized trials. [30] The recent results of the large RECOVERY randomized clinical trial (available to date only as a non-peer-reviewed preprint) have greatly increased the level of evidence on this topic and support the conclusion of our study. [14] Among nearly 15,000 patients randomly allocated in a 1:1 ratio to either usual standard of care plus 150 mg aspirin once daily until discharge or usual standard of care alone, no difference in 1-month mortality was found, including in the subgroup of 3448 patients over 70 years of age. Two large ongoing randomized trials are further evaluating aspirin in outpatients with COVID-19. [31] However, these trials do not focus on older patients at higher risk of $\mathrm{CV}$ events. Moreover, unlike interventional trials, our observational data focus on aspirin prescription prior to the infectious episode. Thus, the lack of correlation between aspirin and prognosis is not explained because it has not been initiated early enough in the COVID-19 course. While there are no interventional data on this subject in older COVID19 patients, preexisting data suggest that preventive aspirin has no benefit in sepsis: in the double-blind randomized controlled ANTISEPSIS trial involving 16,703 healthy subjects over 70 years of age, the rate of death associated with sepsis was not significantly different between the long-term aspirin group and the placebo group. [32] In contrast, the risk of bleeding was significantly higher in the aspirin group.

The interventional data from these two trials support our results but contrast with recent observational data: the large retrospective study by Osborne et al. found that mortality was reduced by half in COVID19 patients who were taking aspirin before diagnosis versus those who were not. [18] However, this study was focused on ambulatory patients with lower CV risk, and the matching procedure was limited by the restricted record of confounders. A recent South Korean nationwide observational study with a similar design found conflicting results. [33] However, similar reductions have been confirmed in the literature, in both hospitalized [9-13] and ambulatory COVID19 patients. [12] Interestingly, using a similar study design in acute pneumonia, Falcone et al. also found that mortality was cut in half in older hospitalized patients taking aspirin when compared with those not taking aspirin. [5]

From a pathophysiological point of view, the overexpression of thromboxane synthase and Toll-like receptor 9 genes, which are involved in platelet aggregation, has been documented in vitro during SARSCoV-2 infection. [3] Just as Keane et al. showed that Streptococcus pneumoniae induced platelet aggregation by interacting with Toll-like receptor 2 (TLR2) in bacterial pneumonia, [34] Zhang et al. recently highlighted that SARS-CoV-2 binds to the platelet ACE2 receptor via its spike protein, resulting in platelet activation, inflammatory cytokine release, and platelet aggregation. [35] Aspirin inhibits platelet aggregation by blocking platelet synthesis of thromboxane A2. As platelet activation and an uncontrolled immune response in the lung are key elements in the pathophysiology of ARDS, [1] aspirin could be expected to have a beneficial effect in severe forms of COVID19. In a meta-analysis of 15 preclinical trials and 8 clinical studies, Panka et al. showed that preventive treatment with low-dose aspirin was associated with 
a decreased risk of ARDS in patients at risk of acute lung injury. [1] The anti-inflammatory effects of aspirin, on the other hand, are only expected at higher doses (650 mg to $4 \mathrm{~g}$ per day), [3] which were not reached in this study. Aspirin also has a proven antiviral effect in experimental models. [3, 4] However, a recent experimental study suggests that the doses usually prescribed in clinical practice are too low to exert this antiviral effect on the lungs. [4]

CV complications are a key issue after acute pneumonia, whatever the pathogen, especially in older age. [36] This problem has also been brought to the forefront in studies of SARS-CoV-2 pneumonia. [17] CV complications notably include post-infectious myocardial infarction, [37] for which aspirin might be expected to have a preventive effect. To the best of our knowledge, there is no specific data on preventive drugs for myocardial infarction incidence after COVID-19. However, in an open randomized clinical trial of 184 patients with high CV risk and acute pneumonia, $\mathrm{Oz}$ et al. showed that aspirin $300 \mathrm{mg}$ introduced at diagnosis significantly reduced the risk of myocardial infarction and CV death at 1 month. [38] Conversely, in a prospective observational study, the rate of myocardial infarction in community-acquired pneumonia did not significantly differ between patients with and without longterm aspirin therapy. Aspirin $100 \mathrm{mg} /$ day appeared to be insufficient to inhibit thromboxane biosynthesis in community-acquired pneumonia and thus prevent platelet activation. [39] Another hypothesis explaining aspirin's lack of benefit is linked to the pathogenesis of post-infectious myocardial infarction. Indeed, post-infectious myocardial infarction is less likely to be due to atherothrombotic events (type 1 myocardial infarction) than to an acute imbalance between myocardial oxygen supply and demand (type 2 myocardial infarction), especially in older patients. [37]

There are several limitations to this study. First, we only included patients with COVID-19 hospitalized in a medical department, and those initially hospitalized in the ICU were not considered. Therefore, these results cannot be extrapolated to more severe patients, especially those under mechanical ventilation. Second, $\mathrm{CV}$ events were not systematically recorded and the causes of death were unknown, so we were unable to evaluate whether aspirin treatment was associated with a lower incidence of $\mathrm{CV}$ complications. Moreover, the potential complications of aspirin were not recorded even though some, especially bleeding, would be expected to be frequent in this frail older population, potentially mitigating the protective effect of aspirin. Third, despite the increased risk of $\mathrm{CV}$ events that persists several months after acute pneumonia, we did not assess long-term outcomes. Fourth, even with an adjustment on comorbidities and clinical parameters at admission, including usual prognostic criteria in COVID-19, the results could be biased by unmeasured confounding due to factors such as frailty, which might not be well captured in routinely collected data. For instance, the unexpected higher rate of transfer to ICU in patients taking aspirin might suggest a surrogate marker of progression to more severe pneumonia; alternatively, it could be explained by a frailer state than patients who were not prescribed aspirin. This pragmatic study remains observational, and only a randomized clinical trial could support a definite statement. However, the RECOVERY study, which supports these results, will likely remain the highest level of evidence on the topic, as interventional data specifically dedicated to the geriatric setting are not expected, and we believe that this large multicenter cohort study fills a gap in the current literature.

In this observational study of frail older inpatients, one-third of the population had died at 1 month of follow-up. This very high rate of mortality highlights the urgent need for therapeutic advances for COVID19. However, our results do not support the use of aspirin in the prevention of death from SARS-CoV-2 pneumonia. Given the conflicting results regarding the benefits of aspirin in COVID-19 in the current literature, there is an urgent need for further research specifically focused on older patients.

Acknowledgements We thank Suzanne Rankin for the English review of the manuscript.

\section{Declarations}

Conflict of interest The authors declare no competing interests.

\section{References}

1. Panka BA, de Grooth H-J, Spoelstra-de Man A, Looney M, Tuinman P-R. Prevention or treatment of ARDS with aspirin: a review of preclinical models and meta- analysis of clinical studies. Shock. 2017;47:13-21. 
2. Gallay L, Tran V-T, Perrodeau E, Vignier N, Mahevas M, Bisio F, et al. Fourteen-day survival among older adults with severe infection with severe acute respiratory syndrome coronavirus 2 treated with corticosteroid: a cohort study. Clin Microbiol Infect. 2021;27:1145-50.

3. Bianconi V, Violi F, Fallarino F, Pignatelli P, Sahebkar A, Pirro M. Is acetylsalicylic acid a safe and potentially useful choice for adult patients with COVID-19? Drugs. 2020;80:1383-96.

4. Gurbel PA, Bliden KP, Schrör K. Can an old ally defeat a new enemy? Circulation. 2020;142:315-7.

5. Falcone M, Russo A, Cangemi R, Farcomeni A, Calvieri C, Barillà F, et al. Lower mortality rate in elderly patients with community-onset pneumonia on treatment with aspirin. J Am Heart Assoc. 2015;4.

6. Hamilton F, Arnold D, Henley W, Payne RA. Aspirin reduces cardiovascular events in patients with pneumonia: a prior event rate ratio analysis in a large primary care database. Eur Respir J. 2020;57:2002795.

7. Srivastava R, Kumar A. Use of aspirin in reduction of mortality of COVID-19 patients: a metanalysis. Int J Clin Pract. 2021;75:e14515.

8. Salah HM, Mehta JL. Meta-analysis of the effect of aspirin on mortality in COVID-19. Am J Cardiol. 2021;142:158-9.

9. Meizlish ML, Goshua G, Liu Y, Fine R, Amin K, Chang $\mathrm{E}$, et al. Intermediate-dose anticoagulation, aspirin, and in-hospital mortality in COVID-19: a propensity scorematched analysis. Am J Hematol. 2021;96:471-9.

10. Liu Q, Huang N, Li A, Zhou Y, Liang L, Song X, et al. Effect of low-dose aspirin on mortality and viral duration of the hospitalized adults with COVID-19. Medicine. 2021;100:e24544.

11. Chow JH, Khanna AK, Kethireddy S, Yamane D, Levine A, Jackson AM, et al. Aspirin use is associated with decreased mechanical ventilation, ICU admission, and inhospital mortality in hospitalized patients with COVID19. Anesthesia \& Analgesia. 2020; Publish Ahead of Print.

12. Savarapu P, Baral N, Adhikari G, Akanbi M, Abdelazeem $\mathrm{B}$, Isa SO, et al. Aspirin use is associated with decreased mortality in patients with COVID-19: a systematic review and meta-analysis. preprint. Infectious Diseases (except HIV/AIDS); 2021.

13. Haji Aghajani M, Moradi O, Amini H, Azhdari Tehrani H, Pourheidar E, Rabiei MM, et al. Decreased in-hospital mortality associated with aspirin administration in hospitalized patients due to severe COVID-19. J Med Virol. 2021;93:5390-5.

14. RECOVERY Collaborative Group, Horby PW, PessoaAmorim G, Staplin N, Emberson JR, Campbell M, et al. Aspirin in patients admitted to hospital with COVID-19 (RECOVERY): a randomised, controlled, open-label, platform trial. preprint. Infectious Diseases (except HIV/ AIDS); 2021.

15. Xu Q, Samanapally H, Nathala P, Salunkhe V, Furmanek $\mathrm{S}$, Cahill MN, et al. Outcomes and risk factors for cardiovascular events in hospitalized COVID-19 patients. J Cardiothorac Vasc Anesth. 2021. https://doi.org/10.1053/j. jvca.2021.03.035.

16. Lala A, Johnson KW, Januzzi JL, Russak AJ, Paranjpe I, Richter F, et al. Prevalence and impact of myocardial injury in patients hospitalized with COVID-19 infection. J Am Coll Cardiol. 2020;76:533-46.

17. Xu H, Hou K, Xu R, Li Z, Fu H, Wen L, et al. Clinical characteristics and risk factors of cardiac involvement in COVID-19. J Am Heart Assoc. 2020;9:e016807.

18. Osborne TF, Veigulis ZP, Arreola DM, Mahajan SM, Röösli E, Curtin CM. Association of mortality and aspirin prescription for COVID-19 patients at the Veterans health administration. PLOS ONE. 2021;16:e0246825.

19. Metlay JP, Waterer GW, Long AC, Anzueto A, Brozek J, Crothers K, et al. Diagnosis and treatment of adults with community-acquired pneumonia. An Official Clinical Practice Guideline of the American Thoracic Society and Infectious Diseases Society of America. Am J Respir Crit Care Med. 2019;200:e45-67.

20. Odille G, Girard N, Sanchez S, Lelarge S, Mignot A, Putot S, et al. Should we prescribe antibiotics in older patients presenting COVID-19 pneumonia? J Am Med Dir Assoc. 2021;22:258-9.

21. Mendes A, Serratrice C, Herrmann FR, Genton L, Périvier S, Scheffler M, et al. Predictors of in-hospital mortality in older patients with COVID-19: the COVID age study. J Am Med Dir Assoc. 2020;21:1546-1554.e3.

22. Katz S, Ford AB, Moskowitz RW, Jackson BA, Jaffe MW. Studies of illness in the aged. The index of ADL: a standardized measure of biological and psychosocial function. JAMA. 1963;185:914-9.

23. Charlson ME, Pompei P, Ales KL, MacKenzie CR. A new method of classifying prognostic comorbidity in longitudinal studies: development and validation. J Chronic Dis. 1987;40:373-83.

24. Lim WS, van der Eerden MM, Laing R, Boersma WG, Karalus N, Town GI, et al. Defining community acquired pneumonia severity on presentation to hospital: an international derivation and validation study. Thorax. 2003;58:377-82.

25. Fine MJ, Auble TE, Yealy DM, Hanusa BH, Weissfeld LA, Singer DE, et al. A prediction rule to identify lowrisk patients with community-acquired pneumonia. $\mathrm{N}$ Engl J Med. 1997;336:243-50.

26. Kalil AC, Metersky ML, Klompas M, Muscedere J, Sweeney DA, Palmer LB, et al. Management of adults with hospital-acquired and ventilator-associated pneumonia: 2016 Clinical Practice Guidelines by the Infectious Diseases Society of America and the American Thoracic Society. Clin Infect Dis. 2016;63:e61-111.

27. Granger E, Sergeant JC, Lunt M. Avoiding pitfalls when combining multiple imputation and propensity scores. Stat Med. 2019;38:5120-32.

28. Xu S, Ross C, Raebel MA, Shetterly S, Blanchette C, Smith D. Use of stabilized inverse propensity scores as weights to directly estimate relative risk and its confidence intervals. Value Health. 2010;13:273-7.

29. Linden A, Samuels SJ. Using balance statistics to determine the optimal number of controls in matching studies. J Eval Clin Pract. 2013;19:968-75.

30. Alves M, Fernandes MA, Bahat G, Benetos A, Clemente H, Grodzicki T, et al. Protecting older patients with cardiovascular diseases from COVID-19 complications using current medications. Eur Geriatr Med. 2021;12:725-39. 
31. Rizk JG, Lavie CJ, Gupta A. Low-dose aspirin for early COVID-19: does the early bird catch the worm? Expert Opin Investig Drugs. 2021;30:785-8.

32. Eisen DP, Leder K, Woods RL, Lockery JE, McGuinness SL, Wolfe R, et al. Effect of aspirin on deaths associated with sepsis in healthy older people (ANTISEPSIS): a randomised, double-blind, placebo-controlled primary prevention trial.Lancet Respir Med. 2021;9:186-5.

33. Son M, Noh M-G, Lee JH, Seo J, Park H, Yang S. Effect of aspirin on coronavirus disease 2019: a nationwide case-control study in South Korea. Med (Baltimore). 2021;100:e26670.

34. Keane C, Tilley D, Cunningham A, Smolenski A, Kadioglu A, Cox D, et al. Invasive Streptococcus pneumoniae trigger platelet activation via Toll-like receptor 2. J Thromb Haemost. 2010;8:2757-65.

35. Zhang S, Liu Y, Wang X, Yang L, Li H, Wang Y, et al. SARS-CoV-2 binds platelet ACE2 to enhance thrombosis in COVID-19. J Hematol Oncol. 2020;13:120.
36. Corrales-Medina VF, Alvarez KN, Weissfeld LA, Angus DC, Chirinos JA, Chang C-CH, et al. Association between hospitalization for pneumonia and subsequent risk of cardiovascular disease. JAMA. 2015;313:264-74.

37. Putot A, Chague F, Manckoundia P, Cottin Y, Zeller M. Post-infectious myocardial infarction: new insights for improved screening. JCM. 2019;8:827.

38. Oz F, Gul S, Kaya MG, Yazici M, Bulut I, Elitok A, et al. Does aspirin use prevent acute coronary syndrome in patients with pneumonia: multicenter prospective randomized trial. Coron Artery Dis. 2013;24:231-7.

39. Cangemi R, Casciaro M, Rossi E, Calvieri C, Bucci T, Calabrese CM, et al. Platelet activation is associated with myocardial infarction in patients with pneumonia. J Am Coll Cardiol. 2014;64:1917-25.

Publisher's note Springer Nature remains neutral with regard to jurisdictional claims in published maps and institutional affiliations. 